\title{
Study on the Effectiveness of Computer-aided Software in Helping College Students Memorize English Words
}

\author{
https://doi.org/10.3991/ijet.v12.i08.7146 \\ Liping $\mathrm{Lu}$ \\ Xi'an International University, Xi'an, Shaanxi 710077, China \\ m18161967856@163.com
}

\begin{abstract}
In this paper, based on cognitive science and foreign language teaching theories, we construct a web-based hybrid learning model, path and platform to cultivate students' comprehensive language application ability. Meanwhile, we choose 1000 English words suitable for college students to memorize, group them into 24 units with the help of the Mint English memory software and study the memory results of these students. By horizontal and vertical comparison of the test data, we conclude that the web-based software is very effective in helping college students memorize English words.
\end{abstract}

Keywords-computer-aided teaching, web-based teaching environment, English words, memory results.

\section{$1 \quad$ Introduction}

In the current era where information technology is developing rapidly, computer networks have been widely applied in many fields, and modern education has begun to extensively use multimedia network in teaching. This teaching method can achieve efficient resource sharing and information exchange, thus having obvious advantages over traditional classroom teaching, such as rich and vivid teaching resources, free and flexible choices of contents, students' great enthusiasm for learning and better teaching quality and efficiency than the traditional method. What is more, in multimedia network teaching, teachers can easily guide students to learn and find the information by themselves to analyze and solve problems. In this method, students take more initiative in learning, which is helpful to the reform of the teaching approach. Multimedia network teaching also helps improve students' basic computer skills and instructional technology quality and abilities, and make them more adaptable to the social development in the future. In addition, web-based teaching can also promote teaching resources [1]. It is expected that this teaching method will cause profound changes in education and teaching ideas, concepts and theories in a certain period in the future.

At present, web-based multimedia teaching is being applied in the English learning field. Some teachers use it to help students memorize English words, which has been quite successful. Memorizing English vocabulary is one of the difficulties in English learning and it is also a weak spot of Chinese learners. Lacking a good language envi- 
ronment, many students find it difficult to remember English vocabulary and thus lose interest in English learning. Having a large vocabulary is a necessary condition for speaking good English; therefore, teachers need to adopt various methods to help students memorize words [2-4].

Practices of and researches on web-based teaching began many years ago. However, little research has been done on its effectiveness in helping students memorize English words and few people study the application of this teaching method among college students' vocabulary learning [5-7]. After intensive exploration, Beijing Kaidi Chenguang Education has developed English vocabulary memorizing courses based on cognitive science and foreign language teaching theories and built an appropriate web-based multimedia teaching and learning platform. Practical experience shows that this platform has effectively improved students' English learning and has been promoted nationwide as a modern education technology subject and received wide attention from scholars [8]. In order to verify whether this software and teaching approach can effectively improve students' memory of English words, we conducted a test in this paper. We chose 612 students who attended this teaching course in 2005 and used this English vocabulary memorizing software to help students memorize 1,000 common words. Then we studied how well they memorized these English words. Test results show that web-based multimedia teaching can significantly improve students' memory of English words.

\section{Computer-aided teaching}

Computer-aided teaching is a new teaching approach, which mainly relies on computer network tools as teaching aids. This teaching approach has its outstanding merits - it can clearly display text and numbers and easily output animations, videos, images and other information, creating a visual and audio environment for students and thereby increasing their learning enthusiasm and efficiency [9-11]. In this approach, students can easily carry out human-machine interaction and efficiently share and search resources, which is much more effective than traditional teaching methods like PPT slides and television.

After years of development and improvement, multimedia teaching has been very mature. It mainly uses computer tools to display multimedia resources like text, audios, images and videos to students to achieve better teaching results [12-14]. This teaching method needs to utilize a variety of technologies and hardware and software, such as computer image processing technology, signal integration, artificial intelligence and image synthesis; therefore, it is technically demanding.

Multimedia technology is integrative and interactive, which are something that television and films do not have. Using multimedia technology in teaching has many advantages. For example, it can stimulate multiple senses of students so that they can receive and process information more efficiently. Through research, some scholars find that the knowledge memory efficiency purely by listening is $15 \%$, while it is $25 \%$ through vision, and that if we use both of them, the memory efficiency can reach $70 \%$. Relevant test and research results also show that the efficiency of multimedia 
teaching is higher than that of the traditional teaching method by $38 \%$, and that the time required is also reduced [15]. In this teach approach, before each lesson, the words to learn and the teaching objectives must be determined and students should also be advised of such in advance.

Computer-aided teaching mainly uses information and computer tools to assist teaching. It is a branch of the information-based teaching modal. In order to facilitate analysis and discussion, the computer-aided teaching model can be generally divided into two types, as shown in Fig.1. From the epistemological point of view, teaching can be divided into objectivism and constructivism, and judged by the way of existence, there are individualism and collectivism. Based on this, we can describe educational and cultural differences using 2-d coordinates. The resulting classification framework of computer-aided teaching models is shown in Figure 1.

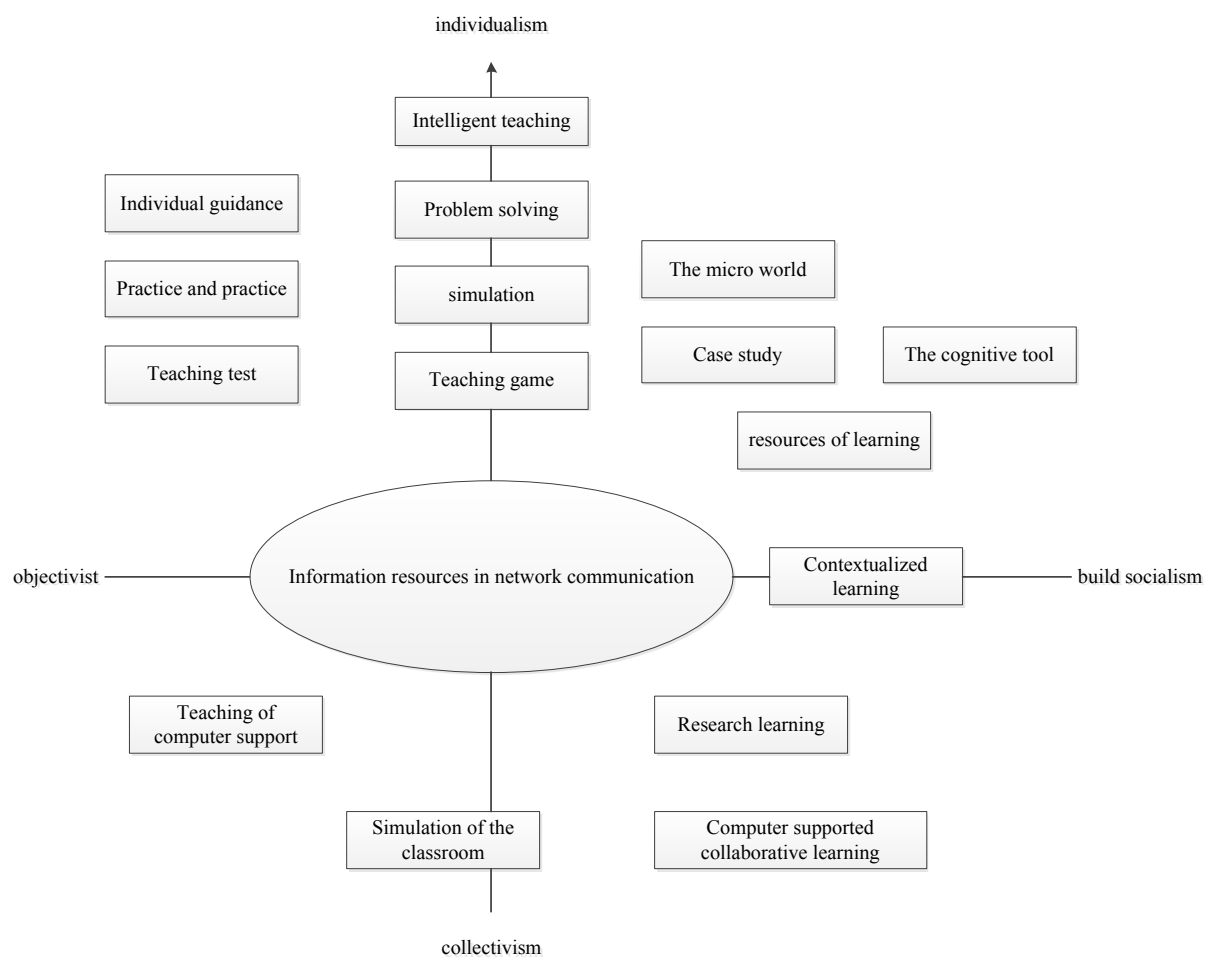

Fig. 1. Classification Framework of Computer-aided Teaching Models

\section{$3 \quad$ Test Design}

\subsection{Research framework}

Overall objective: this paper attempts to study the application of the web-based multimedia teaching in helping college students memorize English vocabulary. In the 
research, it considers relevant theories such as cognitive theory, network teaching theory and learning psychology, and then, based on information and teaching technology, it elaborates on how to improve the English vocabulary memory effect.

Modal design: According to the cognitive learning theory, there are certain interactions between the learning subject and object in the process of learning. Human brain is mainly used to process information and achieves the cognitive purpose during information processing. People living in a certain environment will inevitably exchange information with the environment. In the process of information exchange, individuals play multiple roles, such as information seekers, transmitters, and producers and processors. In the cognition process, individuals do a lot of information processing. The specific learning model is shown in Fig. 2.

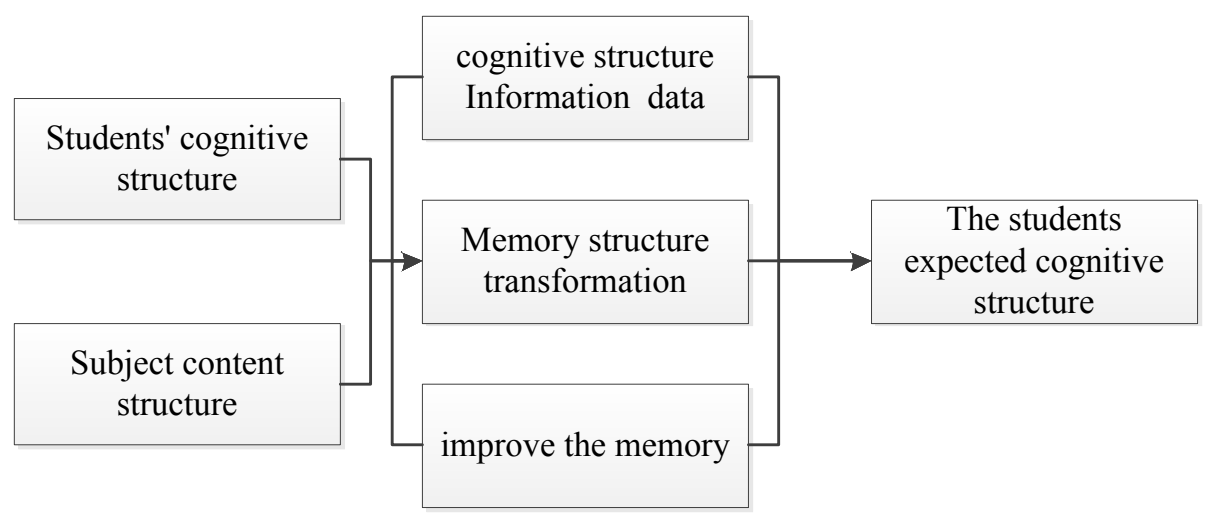

Fig. 2. Cognitive Learning Theory Model

\section{Control of test variables and interference factors}

1. Constrains and management are loose on college students' learning activities, and that is why they are usually passive in learning. In order to better exert the special effects of the Mint English learning software, and effectively control and manage the students' English vocabulary memory results, it is necessary to conduct centralized management on their English learning activities.

2. The Mint English learning model is demanding on teachers' cooperation, requiring that school leaders and English teachers should provide good coordination and cooperation during teaching, which is one of the differences from traditional English teaching methods.

3. Nowadays parents are paying more attention to students' English learning, and many parents assign English learning tasks to their children at home, which also helps students improve their memories of English words. In this study, we also communicated with the parents and asked them to cooperate us in the test. At the same time, the school arranged a vocabulary memorizing activity that lasted for one hour per week and clearly specified the learning objectives [16]. 


\subsection{Test environment and design scheme}

Before the teaching activity, the teacher first informs students of the learning objectives and tasks, and assigns a personal account and password to each student. After understanding the objectives and requirements, students can $\log$ in the server and complete the learning tasks on their own. Some students with strong learning abilities can set their own tasks and establish a learning group with other students to communicate and compete with each other so as to further improve their learning results. Under this teaching mode, the teacher's duty is to organize the class, supervise some students with poor self-discipline, and help and guide those who have questions. After all students complete the tasks, the teacher makes an assessment on the class, that is, to supervise the students entering the examination system in the learning module, and then grade the students' learning results and task completion status through the learning software. The teacher should view their online learning records and results and assign learning tasks for the next class. For some special students, the teacher should also provide special guidance.

\subsection{Analysis of teaching media}

This test employs a piece of highly efficient English learning software - Mint Jiyi. This software is built on the cognitive theory. When we use this software in English vocabulary learning, we can choose the Gagne information processing mode, which is shown in Fig. 3.

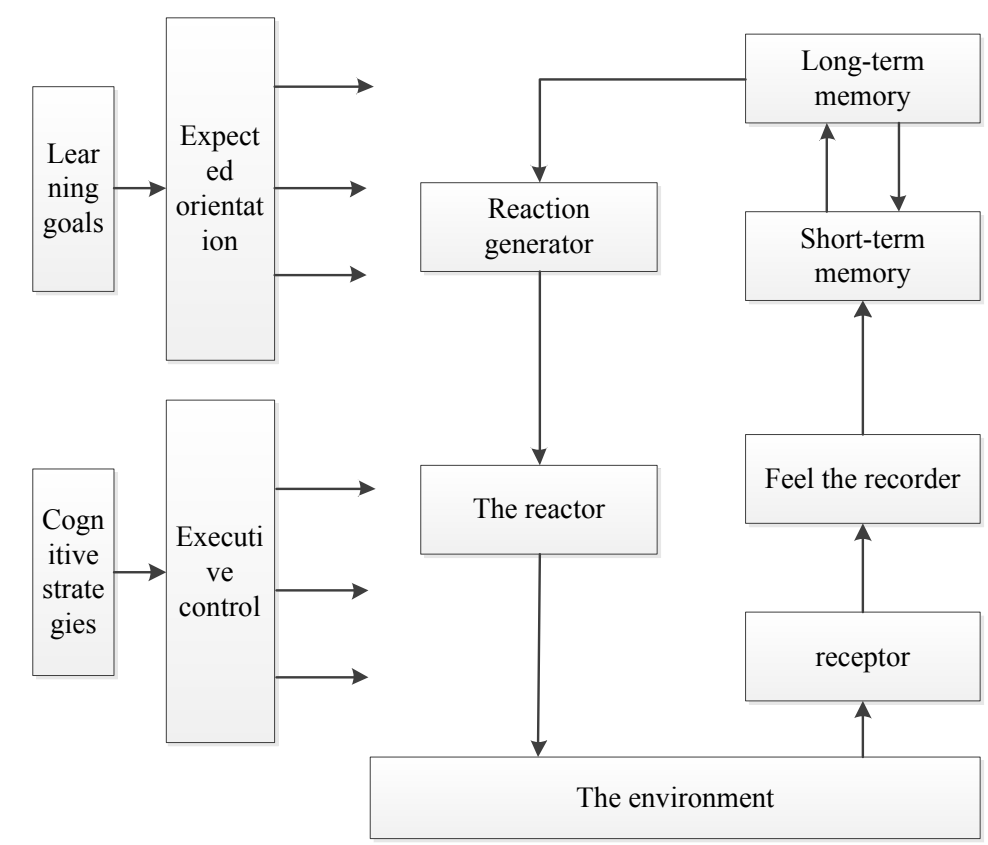

Fig. 3. Gagne Information Processing Mode 


\subsection{Teaching strategies}

In the experimental teaching, we applied the following teaching strategies: hybrid teaching, competitive and mutual-aid learning and role playing. In the research, we chose appropriate teaching strategies according to the specific knowledge points and the teaching contents and requirements, and designed the teaching objectives and requirements for each lesson based on the cognitive teaching theory.

The structure diagram of the teaching design is shown in Fig. 4.

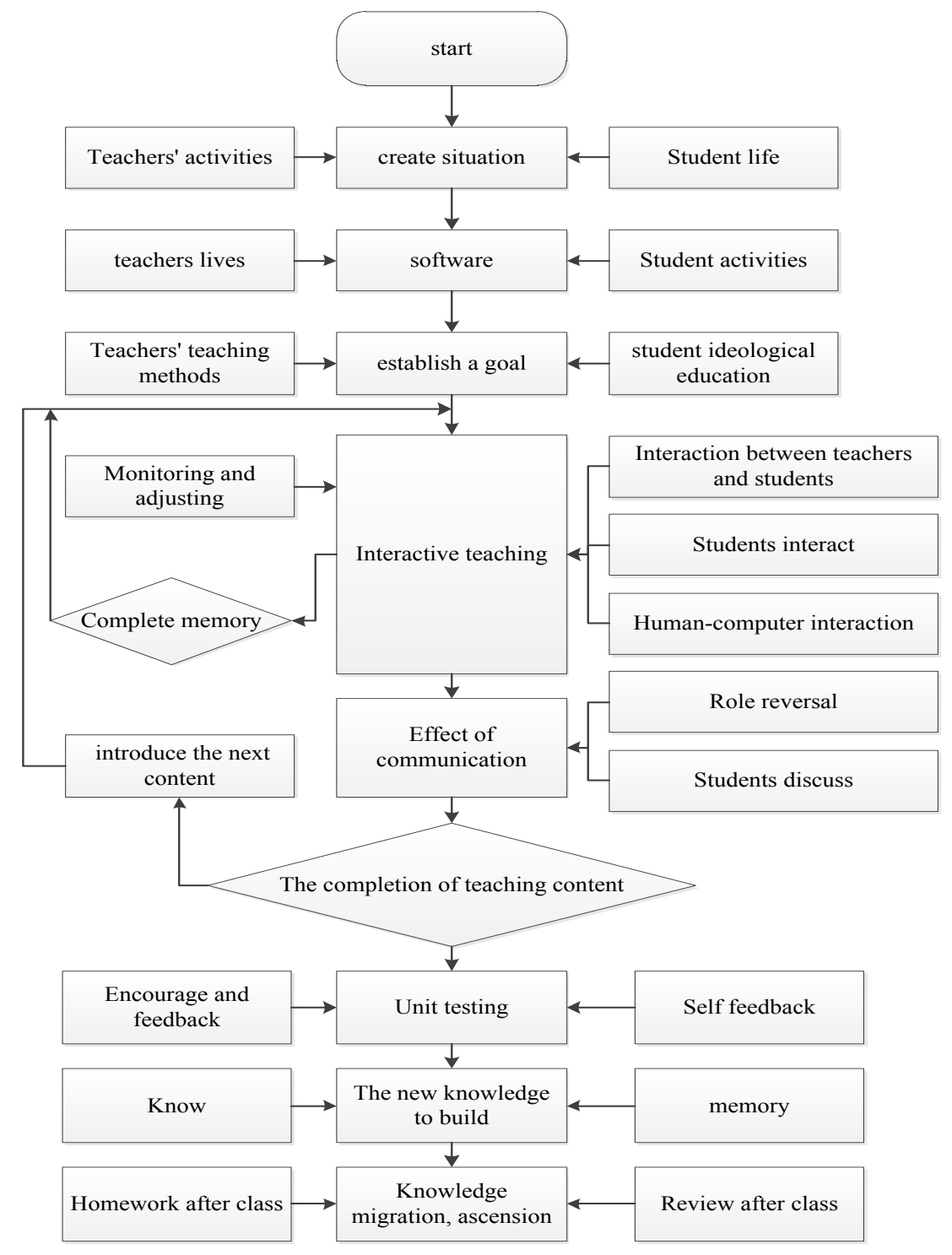

Fig. 4. Structure Diagram of Teaching Design 
In order to improve teaching efficiency, before each unit teaching, the teacher should first divide the students into several groups mainly based on their usual learning results, attitudes, English levels and interests. At the same time the teacher should rationally arrange the seats for students so that students with good and poor students can be evenly distributed and each group has almost the same number of students. In addition, the teacher should advise the students of the words to learn and the teaching objectives for the unit. After understanding them, students can begin the unit learning.

In this way, students can even make their own learning schedules and use Mint English to study by themselves. They can also study with other students in their group as needed and communicate the difficulties they have encountered in the learning process, or ask the teacher questions so as to effectively solve these problems.

\section{Data Statistics and Analysis}

In this research, in order to improve the comparability of test results, the test papers used to examine the students' learning results after a period of learning were the same. The statistics of students' test scores are shown in Table 1.

Table 1. Numbers of Students Giving Correct Answers and the Proportions thereof after the Learning of 1,000 Common Words

\begin{tabular}{|c|c|c|c|c|c|c|c|c|c|c|c|c|}
\hline $\begin{array}{c}\text { Number of correct } \\
\text { answers }\end{array}$ & $<50$ & $\begin{array}{c}51- \\
99\end{array}$ & $\begin{array}{c}100- \\
199\end{array}$ & $\begin{array}{c}200- \\
299\end{array}$ & $\begin{array}{c}300- \\
399\end{array}$ & $\begin{array}{c}400- \\
499\end{array}$ & $\begin{array}{c}500- \\
599\end{array}$ & $\begin{array}{c}600- \\
699\end{array}$ & $\begin{array}{c}700- \\
799\end{array}$ & $\begin{array}{c}800- \\
899\end{array}$ & $\begin{array}{c}900- \\
999\end{array}$ & $>1000$ \\
\hline Number of students & 6 & 34 & 24 & 55 & 116 & 66 & 67 & 115 & 19 & 88 & 6 & 11 \\
\hline Percentage & 1.0 & 5.67 & 3.56 & 8.95 & 19.4 & 11.3 & 10.2 & 18.2 & 3.5 & 14.7 & 1.2 & 1.6 \\
\hline
\end{tabular}

In the test, due to some objective reasons, 2 students were transferred out and another 3 gave up the test, so the final number of students participating in the test was 607.

\subsection{Comparison of results before and after the test}

A bar chart is used here to more visually display the test results. Details of comparison are shown in Fig. 5.

\section{2 $\mathrm{Z}$ test on the vocabulary memory capacity of students in the class of 2005 and 2006}

Statistics (listed in Table 2) show that these two grades of students memorized an average of 467 and 526 words per person. In these two grades, the student numbers are 588 and 607 respectively. We then carried out a variance test on the results, and the sample variance is 26 . 


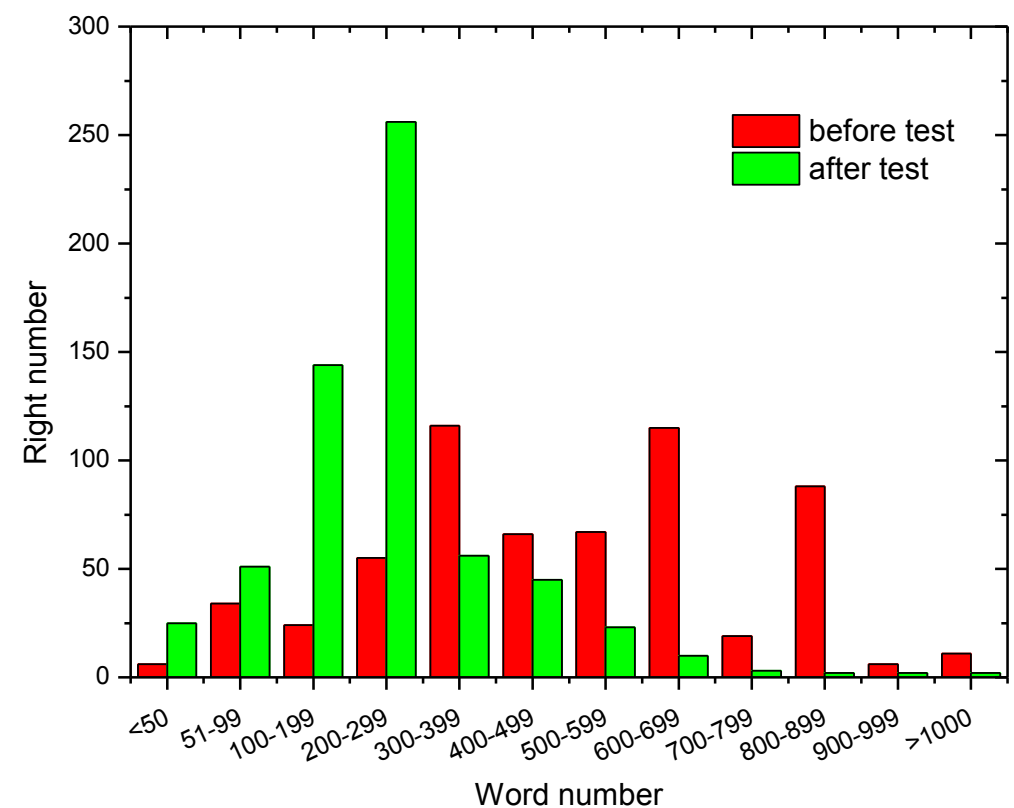

Fig. 5. Results before and after the Test

Table 2. Correlation between $\mathrm{P}$-value and $|\mathrm{Z}|$

\begin{tabular}{|c|c|c|}
\hline$|\mathbf{Z}|$ & $\mathbf{P}$-value & Significant difference degree \\
\hline$|\mathrm{Z}|>2.56$ & $\mathrm{P}<0.01$ & Very significant difference \\
\hline$|\mathrm{Z}|>1.96$ & $\mathrm{P}<0.05$ & Significant difference \\
\hline$|\mathrm{Z}|<1.96$ & $\mathrm{P}>0.05$ & No significant difference \\
\hline
\end{tabular}

Through analysis and comparison, we can see that there are significant differences between the English vocabulary memory results of these two grades of students.

\section{Conclusions}

1. Statistics show that these students have all accomplished the set teaching objectives, and gained good vocabulary memory results. In the learning process, students have effectively improved their listening abilities and learned effective methods to memorize words. When using the software, most students gained a sense of achievement and became more interested in and enthusiastic about learning. Test results also show that the students have also improved their problem-solving speed, thus forming a virtuous circle. After using this software for three months, students have developed more interest and become more confident in English learning, and their scores have been significantly improved, indicating that the intended teaching objectives have been achieved. 
2. Web-based multimedia teaching effectively improves the students' efficiency in memorizing English words, and as a result, students are no longer worried about their vocabulary learning. In addition, this teaching approach also improves their learning initiative and enthusiasm - many students start to learn English by themselves, and in the meantime, develop good learning habits, which further improves their English learning and vocabulary memorizing abilities.

3. Polarization emerges. Under this learning model, teachers no longer play the dominant role, which raises higher requirements for students' independent learning abilities. Some slow learners cannot adapt to this learning model, and as a result, they receive poorer results and some even give up learning. On the other hand, quick learners take more initiative in learning and make the best use of online resources to help them study. In the process, they also fully improve their comprehensive abilities and quality, achieving the intended purposes of informationtechnology-based courses. Therefore, this kind of web-based multimedia teaching model has broad application prospects and needs to be further promoted.

\section{References}

[1] Wang, S.J. (2013). Research on college English autonomous learning mode based on computer networks. Lecture Notes in Electrical Engineering, 227, 739-744. https://doi.org/10.1007/978-3-642-35398-7 93

[2] Yang, Q.H. (2013). Research of college English teaching based on computer network technology. Informatics and Management Science III, 206, 375-382. https://doi.org/10.1007/978-1-4471-4790-9 48

[3] Zhang, Q.L. (2014). Higher vocational college "Computer network technology" course life scene design. Applied Mechanics and Materials, 651-653, 1848-1851. https://doi.org/10.4028/www.scientific.net/AMM.651-653.1848

[4] Song, J., Wu, H. (2011). The English teaching model of cooperative learning in the network environment in higher vocational education. Communications in Computer and Information Science, 218, 100-104. https://doi.org/10.1007/978-3-642-23357-9 19

[5] Rahkila, M., Karjalainen, M. (1999). Evaluation of learning in computer based education using $\log$ systems. Proceedings-Frontiers in Education Conference, 1, 16-21. https://doi.org/10.1109/FIE.1999.839266

[6] Yamamoto, H., Ohtani, A., Kado, T. (1993). Development and evaluation of computermediated education systems for customer engineers. IFIP Transactions A: Computer Science and Technology, 35, 205-214.

[7] Sun, Q.L. (2015). Information under the network environment using computer information security technology. Proceedings-2015 International Conference on Intelligent Transportation, 474-477. https://doi.org/10.1109/ICITBS.2015.122

[8] Jun, Z. (2012). Study of task-based English language teaching using computer network. Proceedings-2012 IEEE Symposium on Robotics and Applications, 600-603. https://doi.org/10.1109/ISRA.2012.6219260

[9] Jing, Z. (2015). Research on adaptive English learning model based on computer network. Revista Iberica de Sistemas e Tecnologias de Informacao, 16, 236-246.

[10] Xu, M.Q. (2011). The research on out-of-class autonomous English learning in computerand network-assisted environment. Advances in Intelligent and Soft Computing, 108, 453459. https://doi.org/10.1007/978-3-642-24775-0 71 
Paper-Study on the Effectiveness of Computer-aided Software in Helping College Students Memorize...

[11] Chen, X.H. (2014). The research on English autonomous learning monitoring theory and application in the network environment. Applied Mechanics and Materials, 644-650, 60796082. https://doi.org/10.4028/www.scientific.net/AMM.644-650.6079

[12] Yang, D.L., Zheng, H. (2010). Research on the framework of new college English teaching mode integrating cooperative and autonomous learning in the network multimedia environment. ICETC 2010-2010 2nd International Conference on Education Technology and Computer, 3, 3256-3259. https://doi.org/10.1109/ICETC.2010.5529552

[13] Han, S.F., Miao, S. (2011). On college English teaching of writing in the network environment. 2011 International Conference on Multimedia Technology, ICMT 2011, 588590. https://doi.org/10.1109/ICMT.2011.6002176

[14] Shen, L.X. (2011). Survey research on college students' English learning anxiety in the computer network environment. ICCSE 2011-6th International Conference on Computer Science and Education, 36, 1010-1012. https://doi.org/10.1109/ICCSE.2011.6028807

[15] Lei, Z., Wei X. (2011). The analysis of English network computer aid test system model and technology selection. 2011 International Conference on Internet Technology and Applications, 1-4, 236-248. https://doi.org/10.1109/ITAP.2011.6006325

[16] Wang, X.M., Yang, Y.J., Wen X. (2011). Research and design of computer-aided English textbook evaluation system. Proceedings of the 1st International Workshop on Education Technology and Computer Science, 3, 913-917. https://doi.org/10.1109/ETCS.2009.741

\section{$7 \quad$ Authors}

Liping Lu is currently a lecturer teaching English at Xi'an International University, 408 Zhangba Road, Shaanxi 710077, Xi'an, China. Lu took foreign language studies at Xi'an International Studies University. Since 2001 till now, she has lectured several courses for English major and non-English major students. Her research is mainly on English teaching, and Second Language Acquisition.

Article submitted 08 May 2017. Published as resubmitted by the author 16 June 2017. 